Commentary

\title{
The Inherent Value of Disability in Higher Education
}

\author{
Benjamin J. Ostiguy \\ Department of Educational Policy, Research, and Administration, University of Massachusetts, Amherst, MA 01003, USA; \\ E-Mail: ostiguy@admin.umass.edu
}

Submitted: 7 September 2018 | Accepted: 11 September 2018 | Published: 6 December 2018

\begin{abstract}
Evidence suggests that college students with disabilities (SWDs) continue to encounter attitudinal and physical barriers while institutions endeavor to offer reasonable supports-mainly in the form of accommodations and modifications. In practice, disability is largely treated as something external and ancillary, with most colleges administering measured allowances, but otherwise managing to avoid change. However, as we proceed into the 21st century, very little seems assured, least of all the status quo. Under the dominant neoliberal regime, virtually everything and everyone is valued in proportion with their perceived economic utility. No longer is higher education widely embraced as a public good. Instead, there is increased scrutiny of the academe with an eye for "value added", and the returns students can expect with regard to careers and earning potential. Viewed through this narrow hegemonic lens, SWDs must assimilate or transcend their perceived impairments if they are to belong. In this commentary, I introduce key concepts from the environmental philosophy/theory of Deep Ecology to the scholarship of disability in higher education and assert that disability in academe has an "intrinsic value", irrespective of expected economic utility. I conclude by discussing ways that the deep valuing of disability can lead to the identification of novel veins of inquiry, bolster critical analyses, and help facilitate meaningful change in uncertain times.
\end{abstract}

\section{Keywords}

disability; Deep Ecology; higher education; neoliberalism

\section{Issue}

This commentary is part of the issue "Students with Disabilities in Higher Education", edited by Geert Van Hove (Ghent University, Belgium/VU Amsterdam, The Netherlands), Minne Bakker (VU Amsterdam, The Netherlands) and Alice Schippers (Disability Studies in the Netherlands/VU Amsterdam, The Netherlands).

(C) 2018 by the author; licensee Cogitatio (Lisbon, Portugal). This article is licensed under a Creative Commons Attribution 4.0 International License (CC BY).

\section{Introduction}

This commentary introduces the philosophy of Arne Naess and "Deep Ecology" to the disability in higher education research literature. Throughout this piece, I offer my thoughts on how research into the experiences of college students with disabilities (SWDs) can derive inspiration and direction from Naess and the Deep Ecology movement, improving our capacity to understand, value, and support college SWDs.

\section{Arne Naess and Deep Ecology}

Contemplative and rugged, Naess conceived and articulated a philosophy of Deep Ecology in nature, regu- larly trudging arduous miles of elevation to Tvergastein, his modest cottage on a slope of a mountain named Hallingskarvet. Naess' chosen ecosystem was alpine, involving organisms and interrelationships that are rather small and easily unnoticed by a distracted, casual observer. It was through his willingness to be present and attentive that Naess came to understand and articulate the value of all organisms, even the inanimate features of a landscape or place. Central to Naess' philosophy is a rejection of the assumption of humanity's primacy among living beings. This controversial idea is well captured in the first three of Naess' eight principles for Deep Ecology (Naess \& Haukeland, 2002, p. 108):

1. All living beings have intrinsic value; 
2. The richness and diversity of life has intrinsic value;

3. Except to satisfy vital needs, humans do not have the right to reduce this diversity and richness.

These deceptively simple assertions stand radically opposed to dominant neo-liberal views that assign value to the natural world proportionate with its potential to address human needs, wants, and interests; and contribute toward economic growth and the production of wealth. Naess proposes an ontology of "unity and diversity" (Naess, 2001, p. 4), one that unites all organisms through the recognition of their interplay of interdependence, without losing the sense of the inalienable dignity of each part.

\section{The Need for a Deep Perspective}

Similar to the external economic forces that inspired Deep Ecology in the environmental sciences, higher education is experiencing scrutiny and demand with respect to its ability to serve neoliberal agendas, such as infusing the workforce with competitive human capital. In this context, efforts to support college SWDs reflect a "power over life" (Foucault, 1990, p. 139), leveraged through the systematic application of law, policy, and administration. For instance, virtually all campuses in the United States require students who experience barriers to inclusion to seek a qualifying disability status by submitting third-party diagnostic documentation. Once qualified, SWDs must engage prescribed policies and procedures in order to request reasonable accommodations. Ironically, these structures-designed to protect and support SWDs-simultaneously stigmatize and differentiate (Loewen \& Pollard, 2010; Markoulakis \& Kirsh, 2013; Weiner, 1999). This reflects a largely unexamined, shallow view of disability on campus; one that allows for minimally responsive efforts (i.e., the least amount required to remain in compliance) with implications for domain specific research, including the scholarship of teaching and learning.

\section{Toward a Deep Campus Ecology}

"Deep Ecology is an invitation to thinking and presents challenging questions and dilemmas" (Devall \& Sessions, 2007, p. x). Through Naess we are entreated to approach our work at the local level, with an awareness of our own incomplete knowing. Deep Ecology asks the observer to adapt and change their sense of self in relation to the environment, and not merely rely upon assumed modes of thinking, perceiving, and understanding-such as the neoliberal default orientation of today's university. Rather than simply asking or assessing if the student with a disability comports with conventional expectations, we should seek to perceive/know/appreciate how they belong in the larger context-contributing towards the comprehension of a bigger picture that may suggest novel veins of inquiry.
We must recognize the intrinsic value of SWDs. A deeper view of disability in higher education can begin with valuing SWDs, beyond their apparent potential to perform or thrive within existing academic or professional structures and domains. Unquestioned, the concept of disability supports unsubstantiated and often arbitrary standards of normalcy. For instance, when instructors design and implement a curriculum, it assumes a status of "normal", with required efforts to accommodate SWDs regarded as exceptions to the norm.

We must Consider what constitutes a "vital need". On occasion, efforts to include SWDs will contradict conventional practice. In response, Deep Ecology calls for a blend of "high level emotional maturity with sophisticated analytical and logical reasoning to draw attention to conflicts between our actions and our fundamental aims" (Glasser, 2002, p. xxi). Beginning at the individual level, in our respective roles, each of us can evaluate if the status quo truly constitutes a "vital need" for students, for the discipline, for the institution, and ultimately for society. If not, then the identification and adoption of inclusive options is suggested.

We can adopt deeply inclusive values and practices. The following items are adapted from a larger list of "Lifestyle Trends within the Deep Ecology Movement" (Naess, 2008, pp. 140-141):

1. Employ accessible and inclusive pedagogies, methods, technologies, and research instruments;

2. Avoid adherence to rigid standards and traditional practices absent of "intrinsic value" or unrelated to "fundamental goals";

3. Before adopting a new or trendy technology, method, or instrument, first consider if SWDs will find it accessible and inclusive;

4. Recognize and value the diverse identities, perspectives, strengths, and challenges represented among college SWDs; cultivate an awareness of intersectional oppressions (e.g., ableism and homophobia);

5. Understand that SWDs are a heterogeneous demographic with identities, priorities, expectations, opinions, and access requirements differing within and among specific disability "types". Note that perspectives on disability vary and evolve, so what is deemed appropriate or supportive may/will vary by generation, culture/ethnicity (e.g., international students), and social/historical context;

6. Employ the concept of universal design in all aspects of your work, including teaching, assessment, research, and service;

7. Develop research questions that account for SWDs and accurately represent/address their perspectives, needs, and sense of dignity;

8. When faced with apparent pedagogic/epistemological dilemmas, err on the side of accessibility and inclusion;

9. Speak out against campus policies, procedures, 
and traditions that are not universally inclusive, or otherwise stigmatize SWDs;

10. Reject the idea that a student's value to a campus or academic discipline is proportional with their apparent potential to contribute toward the economy and the upward distribution of wealth.

\section{Conclusion}

Applied to a college campus, Deep Ecology destabilizes existing structures of normalcy, affording opportunities to promote a deeper approach to inclusion.

\section{Acknowledgments}

I would like to express my gratitude to Professor Ryan S. Wells, the University of Massachusetts Amherst, and Carol R. Ostiguy-Finneran, Northampton, MA, for their feedback and support.

\section{Conflict of Interests}

The author declares no conflict of interests.

\section{References}

Devall, B., \& Sessions, G. (2007). Deep ecology: Living as if nature mattered. Salt Lake City, UT: Peregrine Smith
Books.

Foucault, M. (1990). Right of death and power over life (R. Hurley trans.). In The history of sexuality. Volume 1: An introduction (pp. 134-159). New York, NY: Vintage Books.

Glasser, H. (2002). Introduction. In A. Naess \& P. I. Haukeland (Eds.), Life's philosophy: Reason and feeling in a deeper world (R. Huntford trans., pp. xiii-xxxiv). Athens, GA: University of Georgia Press.

Loewen, G., \& Pollard, W. (2010). The social justice perspective. Journal of Postsecondary Education and Disability, 23(1), 5-18.

Markoulakis, R., \& Kirsh, B. (2013). Difficulties for university students with mental health problems: A critical interpretive synthesis. The Review of Higher Education, 37(1), 77-100.

Naess, A. (2001). Ecology, community, and lifestyle: Outline of an ecosophy (D. Rothenberg trans.). Cambridge: Cambridge University Press.

Naess, A. (2008). The ecology of wisdom: Writings by Arne Naess. Berkeley, CA: Counterpoint.

Naess, A., \& Haukeland, P. I. (2002). Life's philosophy: Reason and feeling in a deeper world (R. Huntford, trans.). Athens, GA: University of Georgia Press.

Weiner, E. (1999). The meaning of education for university students with a psychiatric disability: A grounded theory analysis. Psychiatric Rehabilitation Journal, 22(4), 403-409.

\section{About the Author}

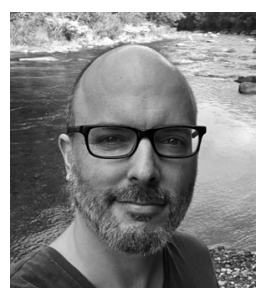

Benjamin J. Ostiguy is a Doctoral student in Higher Education and Associate Director of Operations for disability services at the University of Massachusetts Amherst. As a practitioner-scholar, his areas of inquiry involve college students with disabilities and institutional practices designed to support their full inclusion. He lives in Northampton, MA, with his partner Carol and their daughters, Emma and Gigi. 